\title{
ЭМОЦИОНАЛЬНО-ВОЛЕВАЯ СФЕРА И ЕЕ РАЗВИТИЕ В ИНТЕГРАЛЬНОМ ОБРАЗОВАНИИ
}

\section{EMOTIONAL-VOLITIONAL SPHERE AND ITS DEVELOPMENT IN INTEGRAL EDUCATION}

\section{Abu-Taleb}

Summary: The author believes that in modern education the external locus of control and external factors of student motivation are not important, but the psychosemantic space of integral education is important, which is a system of values, meanings and motives that can induce learning activities. The emotional-volitional sphere of students is formed under the influence not of an external locus of control, but of the social experience that they receive in an integral educational environment. Also, the formation of the emotional-volitional sphere of the individual within the framework of integral education is influenced by: the atmosphere of cooperation and empathy, which can give positive reinforcement to the success of educational activities.

Keywords: integral education, paternalism, external locus of control, emotional-volitional sphere, psychosemantic space, motivation.
A ктуальность темы интегрального образования в современном мире связана с глобализацией, информатизацией и виртуализацией современных социально-культурных пространств. Кроме того, тема интегрального образования важна в контексте растущей человекоразмерности современного мира, опознавания значимости прав человека, установления всеобеего равенства в качестве основополагающего морально-этического принципа. Интегральное образование направлено на формирование аксиосферы человека и развитие его в качестве самоактуализирующейся личности. Отличительной чертой интегрального образования является применение ряда подходов, среди которых: интегративный (в частности, подход интегративной психологии), коммуникативный (ненасильственная коммуникация), коучинговый (преподаватели в интегральном образовании выполняют функции коуча - ментора, помогающего практика).

Еще одной чертой интегрального образования является (выделенная нами) "интегральная субординация" как особый подход к субординации, управлению, начальствованию в образовательной среде. По нашему мнению, классическая субординация в образовании, устоявшаяся со времен популярности прусской системы, устарела, поскольку направлена не на развитие свободной творческой личности, а на формирование идеального исполнителя, нуждающегося в обязательном

\author{
Абу-Талеб Дарья Викторовна \\ Соискатель, Институт психологии творчества \\ onedeka@mail.ru
}

Аннотация: Автор полагает, что в современном образовании важен не столько внешний локус контроля и внешние факторы мотивации учащегося, сколько особое психосемантическое пространство интегрального образования, представляющее собой систему ценностей, смыслов и мотивов, способную побуждать к учебной деятельности. Эмоционально-волевая сфера учащихся формируется под влиянием не внешнего локуса контроля, а социального опыта, который они имеют возможность получить в интегральной образовательной среде. Также на формирование эмоционально-волевой сферы личности в рамках интегрального образования влияет: атмосфера сотрудничества и эмпатии, которая способна дать положительное подкрепление успехам учебной деятельности.

Ключевые слова: интегральное образование, патернализм, внешний локус контроля, эмоционально-волевая сфера, психосемантическое пространство, мотивация.

руководстве сверху. Иными словами, в современной образовательной сфере (в частности, в школьном образовании) необходим переход от вертикальной коммуникации - к горизонтальной. Вертикальная коммуникация также предполагает безусловное подчинение руководителю, что, по нашему мнению, не актуально в современном мире, где каждый должен уметь самостоятельно ориентироваться в смысловом и информационном поле, а также - в ценностном поле, действуя в соответствии с собственными ценностями.

Классическая школьная система отчасти построена на негативной мотивации в виде внешнего локуса контроля и манипуляций негативными санкциями (оценками, угрозами отчисления и т.д.). В современном мире абсолютная актуальность внешнего локуса контроля, в том числе - в образовательной среде, - поддается сомнению. Все больше родителей хотят видеть в своих детях самостоятельных личностей, способных делать собственные жизненные выборы и способных к целенаправленной деятельности с внутренним локусом контроля и внутренней мотивацией.

Итак, еще одним недостатком образовательных систем прошлого является патерналистский подход в образовании. О сущностных чертах патернализма в образовании - статьи М.С. Леонтьевой “Патернализм в обучении и воспитании детей-сирот" [12], А.В. Петрова 
“Патернализм в педагогике: препятствие или основание учебного процесса" [16] и других. Патернализм в образовательной среде выражен, в частности, в авторитарном стиле преподавания и руководства учащимися, в четкой субординации, в определенной системе правил (часто чрезмерной), сформированной без участия самих учащихся (то есть, не предполагающий демократического волеизъявления учащихся). Патернализм в образовании нельзя охарактеризовать как однозначно негативное явление, необходимо оценивать этот феномен во множестве его значимых сторон. Мы, однако, рассматриваем патернализм в современном образовании как пережиток прошлого, некогда необходимый, а сейчас, скорее, негативный. Мы полагаем, что современное образование должно быть нацелено на формирование свободной личности, способной к самоопределению и самоактуализации, что крайне сложно достигается патерналистскими методами воспитания и образования. В этом смысле, мы противопоставляем патерналистскому подходу в образовании - личностный подход, о котором напишем ниже.

Патерналистский подход в образовании несовместим с ценностями интегрального образования, даже если рассматривать исключительно положительные эффекты патернализма, а также - "подлинный патернализм" как его высшую форму, потому что, согласно нашему видению, патернализм - форма несвободы человека. "Г.Д. Левин [11] понимает патернализм как особую форму несвободы (путь к несчастью по воле другого человека), мимикрирующую под бескорыстную, отеческую заботу о благе индивида. Наряду с этим, он считает, что существует подлинный патернализм, т.е. действительно альтруистическая забота одного человека о благе другого, восходящий своими корнями в мировые религии, прежде всего в христианство. Такой подход позволяет выделить признаки абсолютного патернализма. К ним относятся: всеблагость, полное бескорыстие (идеальный «патрон» не ожидает от своего клиента эквивалентной услуги), всеведение патрона (ни благие цели, ни их бескорыстие не имеют никакого значения, если патрон не знает, что есть благо и какие пути ведут к нему) и всемогущество патрона (способность не только в воображении, но и в реальности преодолеть все трудности, возникающие к сверхцели абсолютного патернализма - вечному и полному блаженству объекта патерналистического воздействия) [12]. Исходя из приведенных признаков, можно сделать вывод, что идеальный патрон - это абсолют в нравственном, интеллектуальном и практическом смысле. Однако его всеблагость и абсолютное бескорыстие превращают клиента в полного потребителя, подчиняющегося воле патрона".

По нашему мнению, в современном образовании место патрона должен занять наставник, коуч, который не руководит подопечным, а действует с ним заодно, раскрывая, при помощи системы наводящих во- просов и других приемов взаимодействия, потенциал личности. Коучу нет необходимости быть "абсолютом в нравственном смысле", достаточно руководствоваться в своей деятельности системой ценностей, адекватной современному гуманистическому человекоразмерному мировоззрению, а также - таблицей коучинговых компетенций. Таким коучем должен, очевидно, стать учитель (преподаватель). Стоит отметить также, что коуч (и учитель, применяющий в работе коучинговые методы), воспринимает коучи (ученика) не как объект образовательного процесса, а как полноценного его субъекта. С этой точки зрения, действенными в процессе обучения могут быть наводящие вопросы (коучинговые вопросы), направленные не столько на контроль знаний ученика, сколько на выявление его собственного мнения по поводу некоторого предмета обсуждения.

Актуальность внедрения коучингового подхода в образовании соответствует современным требованиям ФГОС. На сайте урок.рф в статье про «Коучинговый подход в учебно-воспитательном процессе как технология реализации современных требований ФГОС» сообщается о появлении в некоторых учебно-образовательных заведениях такого подхода с 2010 года. «Коучинг, представляет собой форму консультативной поддержки, которая помогает человеку достигать значимых для него целей в оптимальное время путем мобилизации внутреннего потенциала, развития необходимых способностей и формирования новых навыков». [15] В своей деятельности, технологию коучинга взяла за основу, чтобы проследить за душевным состоянием ученика, его воспитанностью и процессом формирования личности по разным жизненно важным направлениям». Баравкова М.М. в своих исследованиях склоняется к мнению о том, что: “Концепция коучинга, как эффективная, апробированная на практике система развивающего взаимодействия, максимально соответствует концептуальным основам современного образования, обозначенным в нормативно-правовых актах и Федеральным государственным образовательным стандартом" [5].

О системе ценностей в интегральном образовании следует, на наш взгляд, упомянуть отдельно. Ценности в интегральном образовании не "прививаются извне", не формируются целенаправленно воспитательными приемами, а воспитываются средой - когнитивно-коммуникативным топосом (пространством) интегрального образования. Мы исходим из представления о миметичности (подражательности) детства и убежденности в том, что пример воспитывает лучше, чем образовательный прием, а среда - лучше, чем отдельный наставник. В этом смысле раскрывается еще один аспект интегральности в интегральном образовании: среда воспитывает во взаимодействии ее отдельных компонентов - коммуникативной этики, ценностей, разделяемых участниками коммуникации, особенностей поведения окружающих, характером их сотрудничества и т.д. Можно сказать, 
что когнитивно-коммуникативный топос интегрального образования создается при участии ее организаторов (преподавателей и т.д.), а также каждого из учащихся как участников образовательного пространства.

Говоря о топосе интегрального образования, заметим его взаимосвязанность с интегральной субординацией, а также еще одной особенностью интегрального образования [3], отмеченной нами в других статьях (в частности, в статье «Интегральное образование как среда формирования навыков фрилансера») [2]. Под упомянутой особенностью мы имеем в виду непрерывность интегрального образования, его адаптивность, способность продолжаться в разных жизненных контекстах и ситуациях (не только в пространстве школьных аудиторий, но и дома, на отдыхе и т.д.). Интегральная субординация [4] как здоровое горизонтальное взаимодействие учащегося и преподавателя (ученика и учителя) предполагает адаптивность, пластичность социальных ролей и разных жизненных контекстах: так, учитель может быть другом ученика, находясь в пространстве школы, мама (а мы полагаем, что родители - также полноправные участники интегральной образовательной среды) может быть помощником учителя или учителем; учитель раскрывается как человек, находясь в образовательном контексте, и, в другое время, - продолжает быть учителем во время совместного досуга с учащимися (например, поездки в лес, в музей, театр, другие города и страны). Это смешение контекстов и социальных ролей не только помогает учителю и ученику раскрыться с разных сторон, стать ближе и избежать стресса, связанного с привычной субординацией, но и делает процесс образования по-настоящему непрерывным. Непрерывность этого процесса обеспечивается не патернализмом, а личностным подходом в образовании, способностью когнитивно-коммуникативного образовательного пространства раскрыть внутренний потенциал учащегося и помочь ему найти собственную мотивацию, сформировать внутренний локус контроля, помочь целенаправленно распоряжаться собственным временем.

Таким образом, мы переходим ко второй смысловой части нашей статьи, посвященной развитию эмоционально-волевой сферы учащихся в интегральном образовании. Эмоционально-волевая сфера включает в себя такие значимые для интегрального образования компоненты, как: целеполагание, мотивация (автономная внутренняя мотивация), воля, самооценка и т.д. Мотивация учащегося относится к его эмоционально-волевой сфеpe.

Л.С. Выготский в своих трудах отмечал решающую зависимость качества усвоения знаний и умений, полученных в процессе воспитания и обучения субъекта, от его эмоционального отношения к людям и окружающей предметной среде [7].
Широта эмоциональных переживаний помогает человеку более чутко понимать происходящее и сопереживать другим людям, понимать их межличностные отношения, осознавать самого себя, понимать свои возможности, способности, достоинства и недостатки. Становление личности ребенка зависит от формирования его эмоционально-волевой сферы и личного опыта.

Основные компоненты эмоционально-волевой сферы - направленность личности, эмоции и воля. При этом под направленностью личности мы понимаем систему побуждений, устойчиво характеризующих человека: его желания, стремления, и наоборот - объекты, против которых он готов бороться; его миропонимание.

Развитие эмоционально-волевой сферы школьника не может успешно проходить, по нашему мнению, в условиях гиперопеки, контроля и школьного патернализма. Это связано с тем, что постоянный внешний локус контроля мешает развитию личности: ее собственного миропонимания, в том числе - осознаванию ее собственных, не навязанных извне, желаний, стремлений, предпочтений. По нашему мнению,

Как отмечает А.В. Морозова, эмоциональное развитие играет важную роль в становлении личности школьника, поскольку недостаточность развития эмоционально-волевой сферы влечет за собой затруднение процесса саморегуляции учебной деятельности. [13].

Особенно актуален вопрос развития эмоциональноволевой сферы в младших классах, что связано с эмоционально-интеллектуальной незрелостью детей младшего школьного возраста, а также возрастными особенностями саморегуляции учебной деятельности. Как отмечают педагоги, необходимо развивать у младших школьников как эмоционально-волевую сферу в целом, так и навыки саморегуляции, что, в конечном счете, является элементами развития личности в целом, а также - необходимыми компонентами воспитания.

Как указано в статье 2 в редакции Федерального закона об образовании от 31.07.2020 № 304-Ф3 ("Основные понятия, используемые в настоящем Федеральном законе"): "воспитание - деятельность, направленная на развитие личности, создание условий для самоопределения и социализации обучающихся на основе социокультурных, духовно-нравственных ценностей и принятых в российском обществе правил и норм поведения в интересах человека, семьи, общества и государства... [1].

Эмоционально-волевая сфера детей младшего школьного возраста отличается такими особенностями: непосредственность в проявлении эмоций, бурная эмоциональная реакция на события, впечатлительность, низкие способности к управлению эмоциями, эмоцио- 
нальный интеллект, находящийся в процессе развития. Перед системой образования стоит задача по развитию эмоционально-волевой сферы, а также эмоционального интеллекта ученика.

Развитие эмоционально-волевой сферы у детей с задержкой развития. "Эмоции считаются одним из главных механизмов саморегуляции психической деятельности и поведения, предназначенных для удовлетворения необходимых потребностей" [6]. Эмоции - одна из форм психического отражения объективной реальности, элемент поведенческой адаптации (приспособления). Эмоции способствуют приобретению личного опыта, а также выработке желательных и избавлению от неэффективных форм поведения человека. Формирование эмоционально-волевой сферы - важнейшее условие развития личности человека. Этапы генезиса эмоционально-волевой сферы предполагают создание устойчивых эмоциональных взаимоотношений с окружающими людьми, формирование ценностно-нормативного аспекта, в том числе - круга обязанностей, идеалов и норм поведения, служащих регуляторами повседневной деятельности. В.К. Вимонас писал, что “многообразие человеческих эмоций связано со сложностями человеческих желаний и потребностей, условий для их реализации и действий, направленных на их достижение" [6]. К. Изард отмечал в своих работах чувственную и функциональную стороны эмоций: «Эмоция - это нечто, что переживается как чувство, которое мотивирует, организует и направляет восприятие, мышление и действие» [10]. Иными словами, эмоция по определению связана с волей, поскольку служит «мотивирующим и направляющим чувством».

Важно отметить, что эмоции - не исключительно психологическое, но сложное, комплексное психофизиологическое - как явление, так и состояние. То есть - на характер эмоций (их возникновение и проживание) влияют физиологические факторы. Это значимо в случае, когда речь идет о эмоционально-волевой сфере детей, поскольку в этом аспекте необходимо понимать биологические (физиологические) основания формирования эмоциональной (эмоционально-волевой) сферы взрослеющего человека.

«Эмоции могут выражать положительные и отрицательные переживания, могут оказывать стимулирующий и тормозящий эффект на поведение и деятельность, характеризуются интенсивностью переживаний, длительностью протекания эмоционального реагирования и предметностью, что объясняется уровнем связи с конкретным объектом или произошедшей ситуацией» [6]. Вышеописанное позволяет думать об элементах эмоционально-волевой сферы - эмоциях и воле - как тесно взаимосвязанных явлениях, где эмоции оказывают значительное влияние на волю человека (и его желание той или иной деятельности), а воля может служить основой для появления тех или иных эмоций. По нашему мнению, понимание компонентов эмоционально-волевой сферы как взаимосвязанных значимо с точки зрения исследования образовательной среды и ее когнитивнокоммуникативных пространств. Так, "негативные" эмоции, полученные в процессе образования, в школьной среде, могут существенно тормозить мотивацию к учебе и, соответственно, учебные успехи. Позитивные эмоции, напротив, могут создавать положительное эмоциональное подкрепление желаемого поведения (в частности, учебного).

Вопрос о нейрофизиологии эмоций актуализируется в связи с дискуссией об эмоционально-волевой сфере детей школьного возраста. Так, в дискуссиях можно встретить аргументы о незрелости подкорковых зон головного мозга детей и подростков определенных возрастов как обоснование необходимости внешнего локуса контроля в образовательной среде. В этом контексте упомянем исследования Е.Д. Хомской и Н.Я. Батовой, которые выделяют два направления в исследовании эмоциональной сферы: узкий локализационизм и системный подход. «Сторонники узкого локализационизма считают, что проявление базовых эмоциональных реакций связано с работой подкорковых центров головного мозга. Однако исследования показали, что раздражения конкретных зон головного мозга вызывают лишь незначительное число эмоций. Другие эмоции не имеют постоянного местоположения и образуются как условно-рефлекторные сочетания базовых эмоций, возникающие в ходе приобретения социального опыта. На сегодняшний день лимбическая система выступает как организатор разных систем мозга, участвующих в обеспечении эмоционального реагирования. Центральное звено лимбической системы имеет взаимосвязь, как с подкорковыми мозговыми структурами, так и с большими полушариями коры головного мозга. Система работы структур головного мозга в регуляции эмоций доказаны в ряде исследований на животных и клиническими наблюдениями за людьми» [17]. В связи с этим мы можем отметить, что зрелость неокортекса, хотя и влияет на генезис эмоционально-волевой сферы, не является единственным фактором ее формирования. Также в формировании эмоций и воли человека существенную роль играет социальный опыт, который невозможно получить в достаточном объеме в «патерналистически-ориентированной» системе образования. Лимбическая система, которая формируется под влиянием социального опыта, ответственна за формирование эмоций, воли и мотивации, участие в ориентировочно-исследовательской деятельности. Также лимбическая система отвечает за качество кратковременной и долговременной памяти человека. В книге «Физиология эмоций» о лимбической системе написано: «в конце концов, была сформулирована теория о лимбической системе, представляющей собой совокупность структур головного мозга, принимающих участие в образовании эмоционально-мотивационного поведения. Согласно этой теории эмоции 
возникают в гиппокампе, оттуда направляются в гипоталамус, таламус и затем в поясную извилину - круг Папеца» [8]. Интегральное образовательное пространство, нацеленное на получение участниками самостоятельного социального опыта (в том числе - опыта социального взаимодействия), опосредованно влияет на развитие лимбической системы и эмоционально-волевой сферы учеников.

Таким образом, трансформация влияния внешнего локуса контроля в интегральном образовании не оказывает негативного влияния на успешность обучения. Под «трансформацией внешнего локуса контроля» мы понимаем ситуацию отсутствия патернализма в образовательной среде, а также распределение ответственности (за ход работы и успехи работы) в когнитивно-коммуникативном топосе образования между всеми его участниками. В результате, ученики, получающие положительное подкрепление в ходе командной учебной деятельности, не нуждаются в патерналистском управлении этой деятельностью. Желание учиться и работать образуется в интегральном когнитивно-коммуникативном пространстве не под влиянием конкретного стимула, а в силу воздействия особой аксиосферы, сформированной в пространстве интегрального образования. Ценности такой аксиосферы - сотрудничество, командная работа, важность личности, мыслей каждого участника, непрерывность образования, знания как ценность, понимание того, что индивидуальный успех влечет за собой успех команды в целом и т.д.

Эмоционально-волевая сфера учеников в интегральном образовании развивается также и благодаря особой атмосфере сотрудничества и эмпатии, позитивного эмоционального отклика, сопровождающего учебнопознавательную деятельность. Мы говорим об особом «психосемантическом пространстве» интегрального образования, сформированном на пересечении значимых персональных значений, ценностей, смыслов и норм, с ориентацией на общечеловеческие гуманистические ценности, а также ценности личностного подхода в педагогике. Фактически, психосемантическое пространство интегрального образования оказывает положительное влияние на эмоционально-волевую сферу его участников, стимулируя интерес к учебе. В психосемантическом пространстве интегрального образования межличностное соперничество (и сопутствующее ему внешнее оценивание успехов и неуспехов) уступает место сотрудничеству в дружелюбной командной обстановке. Отметим, что отсутствие внешнего оценивания успехов и неуспехов способствует формированию здоровой самооценки в Я-концепции личности.

Психосемантическое пространство интегрального образования можно назвать также “пространством ценностных ориентаций" [9].
Основатель отечественной теории отношений В.М. Мясищев обращал внимание на то, что в ценностях и идеалах человека могут быть заключены побуждения к действию (так же, как и в потребностях): «так, потребность и идеал могут вступать в конфликт друг с другом, вместе с тем в идеале или в требованиях долга так же, как и в потребностях, заключено внутреннее побуждение к действию» [14]. Соглашаясь с этим утверждением Мясищева, мы видим его как доказательство влияния психосемантического пространства на развитие ценностноволевой сферы учащихся, а также на побуждение их к учебной, творческой, познавательной деятельности.

Таким образом, на вопрос о том, что именно будет побуждать учащихся к необходимой деятельности в рамках системы интегрального образования, учитывая тот факт, что персонализированный внешний локус контроля и оценивания (учитель, директор, завуч как лица, выполняющие функцию контроля и оценивания) в подобных пространствах не приветствуется, - мы можем ответить, что функцию "побуждающего к действию и деятельности" берет на себя психосемантическое пространство интегрального образования. Учитель в этом пространстве остается нравственно-ценностным ориентиром, экспертом в определенной области знаний, а также выполняет функции тьютора, коуча образовательного процесса и, одновременно, - партнера по командной деятельности.

Таким образом, мы можем сделать следующие выводы:

1. Классическая субординация в образовании (закрепившаяся под влиянием популярности «прусской системы»), направлена не на развитие свободной творческой личности, а на формирование идеального исполнителя, нуждающегося в обязательном руководстве сверху, и устарела в современном мире.

2. Традиционная школьная система построена, среди прочего, на негативной мотивации в виде внешнего локуса контроля и манипуляций негативными санкциями. В современном мире внешний локус контроля как необходимый фактор мотивации к учебной деятельности теряет актуальность.

3. Патернализм в современном образовании - пережиток прошлого. Современное образование должно быть нацелено на формирование свободной личности, способной к самоопределению и самоактуализации, что идет вразрез с патерналистскими методами воспитания и образования. Также патернализм противоречит ценностям интегрального образования.

4. Интегральное образование - новая система образования, построенная по принципам "новаторства, эффективности и альтернативы", предполагающая формирование особых (интегральных) 
образовательных пространств, в которых учащийся получает не только знания, но и навыки их интеграции в жизнь, а также опыт горизонтальной коммуникации и командного взаимодействия с соучениками и учителями. Также интегральное образование нацелено на формирование у учащегося "интегрального видения" объективной реальности на основе полученных знаний.

5. Важным является вопрос о развитии эмоционально-волевой сферы учащихся в рамках системы интегрального образования, а также - вопрос о возможности мотивации учащихся к учебной деятельности при отсутствии внешнего локуса контроля.

6. Отвечая на этот вопрос, мы исходим из убежденности в том, что в современном образовании важен не столько внешний локус контроля и внешние факторы мотивации учащегося (например, система оценивания или сопернический компонент учебной деятельности), сколько особое психосемантическое пространство интегрально- го образования, представляющее собой систему ценностей, смыслов и мотивов, способную побуждать к учебной деятельности. Психосемантическое пространство интегрального образования дает учащемуся возможность сформировать свои собственные ценности и смыслы в рамках учебной деятельности.

7. Эмоционально-волевая сфера учащихся формируется не под влиянием внешнего локуса контроля, а под влиянием социального опыта, который они имеют возможность получить в интегральной образовательной среде. Также на формирование эмоционально-волевой сферы личности в рамках интегрального образования влияет доброжелательная эмпатичная среда: атмосфера сотрудничества и эмпатии, позитивного эмоционального отклика, которая, по нашему мнению, способна дать положительное подкрепление успехам учебной деятельности лучше, чем внешнее оценивание.

\section{ЛИТЕРАТУРА}

1. Федеральный закон об 0бразовании в Российской Федерации. В редакции Федерального закона от 31.07.2020 № 304-Ф3 - Режим доступа: https://еdu. gov.ru/about/

2. Абу-Талеб Д.В., Сандалова А.В. Интегральное образование как среда формирования навыков фрилансера // Современное образование: опыт прошлого, взгляд в будущее. - 2021. - С.163-172

3. Абу-Талеб Д.В. Коучинг как инструмент развития личности учащегося в интегральном образовании // Universum: психология и образование : электрон. научн. журн. 2021. 7(85). URL: https://7universum.com/ru/psy/archive/item/11916 (дата обращения: 08.06.2021).

4. Абу-Талеб Д.В. Межпоколенная коммуникация и феномен затрудненного общения в контексте современного образования личности. Вестник интегративной психологии // Журнал для психологов. Вып. 22. /Под ред. В.В. Козлова, Ш.Р. Баратова, М.Н. Усмановой. - Бухара - Ярославль: МАПН, 2021. - 252 с. C. $5-10$

5. Баравкова М.М. Коучинг как инструмент развития межличностных отношений младших подростков // Мотивация и рефлексия личности: теория и практика. - Материалы конференции “Мотивация и рефлексия личности" (31 октября 2017). - 2018. - С.44-49

6. Вимонас, В.К. Психология эмоциональных явлений / В.К. Вимонас. - М.: Просвещение, 2006. - 132 с.

7. Выготский, Л.С. Лекция по психологии [Текст] / Л.С. Выготский. - СПб.: Союз, 1997. -260 с.

8. Гиноян Р.В., Хомутов А.Е. Физиология эмоций. Нижний Новгород: Изд-во Нижегородского госуниверситета. 2010. 66 с.

9. Дементьева 0.С. Психосемантическое пространство ценностных ориентаций личности в подростковом возрасте // 0бразование и саморазвитие. - 2013. - № 2(36). - С.183-187

10. Изард, К.Э. Психология эмоций / К.Э. Изард. - СПб.: Питер, 2007. - 464 с.

11. Левин Г.Д. Свобода и покинутость. Методологический анализ // Вопросы философии. 1997. № 1. С. 57-68.

12. Леонтьева М.С. Патернализм в обучении и воспитании детей-сирот // Известия ТулГУ. Гуманитарные науки. - 2013. - № 3-2. - С.143-149

13. Морозова А.В. Особенности эмоционально-волевой сферы личности младших школьников // Студенческая наука и XXI век. - 2016. - № 1. - С.76-83

14. Мясищев, В.Н. Психология отношений / В.Н. Мясищев; под ред. А.А. Бодалева. - М.: Ин-т практической психологии; Воронеж: МОДЭК, 1998. - с.77

15. Педагогическое сообщество «Урок.рф». - [Электронный источник]. - Режим доступа: https://ypoк.pф/library/kouchingovij_podhod_v_uchebno_ vospitatelnom_p_225956.html (дата обращения: 06.05.2021)

16. Петров А.В. Патернализм в педагогике: препятствие или основание учебного процесса // Вестник МИТХТ. Серия: гуманитарные науки и экология. - 2015. - № 2. - T.2. - C.20-25

17. Хомская, Е.Д. Мозг и эмоции (нейропсихологическое исследование) / Е.Д. Хомская, Н.Я. Батова. - М.: Букинист, 1998. - 268 с. 